\title{
An Infrared Spectroscopic Investigation on the Complexes Formed Between Boric Acid and Salicylate Ions
}

\author{
RAGNAR LARSSON and GENNARO NUNZIATA* \\ Inorganic Chemistry 1, Chemical Center, University of Lund, \\ Box 740, S-220 07 Lund 7, Sweden
}

\begin{abstract}
The infrared spectra of the salicylate-boric acid complexes in aqueous solution have been recorded in the range $1500-800 \mathrm{~cm}^{-1}$. The structure of the complexes is discussed and the stability con. stants have been determined from the spectral data $\left(\beta_{1}=17 \pm 3\right.$ $\mathrm{M}^{-1}, \beta_{2}=9 \pm 6 \mathrm{M}^{-2}$ at $\mathrm{pH}=7$ ).
\end{abstract}

Following an investigation by infrared spectroscopic techniques on the $F$ complexes formed in aqueous solution between boric acid and lactate ions, ${ }^{1}$ we have endeavoured to investigate in the same manner the complexes formed between boric acid and salicylate ions. It is well known that salicylate ions form complexes with boric acid (e.g. Refs. 2 and 3). As in the previous investigation, ${ }^{1}$ we have chosen to perform the measurements at such a $\mathrm{pH}-$ in this case $\mathrm{pH}=7$ - that the predominating boron species is the boric acid.

Then the reactions by which the complexes are formed can be written as

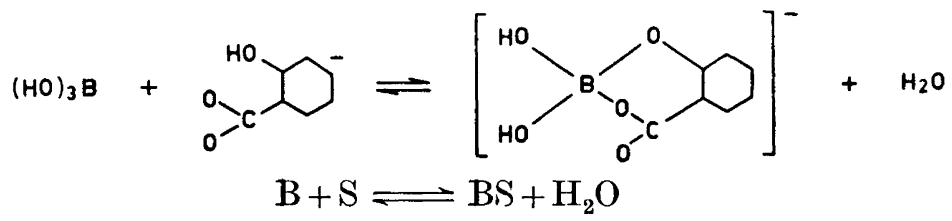

or

$$
\mathrm{B}+\mathrm{S} \rightleftharpoons \mathrm{BS}+\mathrm{H}_{2} \mathrm{O}
$$

with the stability constant

$$
\beta_{1}=[\mathrm{BS}] /[\mathrm{B}][\mathrm{S}]
$$

and

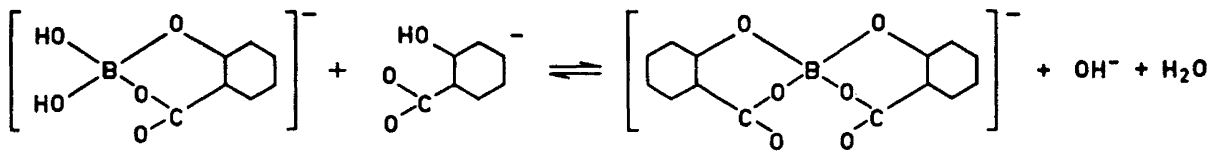

* Present address: Product Research Department, European Technical Center, Procter and Gamble Co., Bruxelles, Belgium.

Acta Chem. Scand. 26 (1972) No. 4 
or

$$
\mathrm{BS}+\mathrm{S} \rightleftharpoons \mathrm{BS}_{2}+\mathrm{OH}^{-}+\mathrm{H}_{2} \mathrm{O}
$$

with the formation constant $K_{2}{ }^{\prime}$

$$
K_{2}^{\prime}=\left[\mathrm{BS}_{2}\right]\left[\mathrm{OH}^{-}\right] /[\mathrm{BS}][\mathrm{S}]
$$

At a constant $\mathrm{pH}$ one can write

$$
K_{2}=K_{2}^{\prime} /\left[\mathrm{OH}^{-}\right]=\left[\mathrm{BS}_{2}\right] /[\mathrm{BS}][\mathrm{S}]
$$

and the stability constant $\beta_{2}$

$$
\beta_{2}=\left[\mathrm{BS}_{2}\right] /[\mathrm{B}][\mathrm{S}]^{2}
$$

\section{EXPERIMENTAL}

The experimental technique was the same as before, i.e., the spectra were recorded with a Perkin Elmer 521 grating spectrophotometer, using IRTRAN 2 windows in the cells, and the cell-thickness was defined by a platinum spacer of about $20 \mu$. All solutions were $3 \mathrm{M}$ in respect to $\mathrm{NaCl}$. The reference cell also contained $3 \mathrm{M} \mathrm{NaCl}$, expect for some cases when some boric acid was added to compensate for excess boric acid in the sample solution.

As the thickness of the cells was constant during this work only absorbance data are given, not absorption coefficients.

\section{RESULTS}

Some representative spectra are given in Figs. 1 and 2 . Fig. $1 \mathrm{~b}$ represents the case when $C_{\mathrm{B}}=1.0 \mathrm{M}$ and $C_{\mathrm{S}}=0.5 \mathrm{M}$. Hence it is to be expected that the equilibrium (1) is shifted towards the right hand side so that most of the sali-

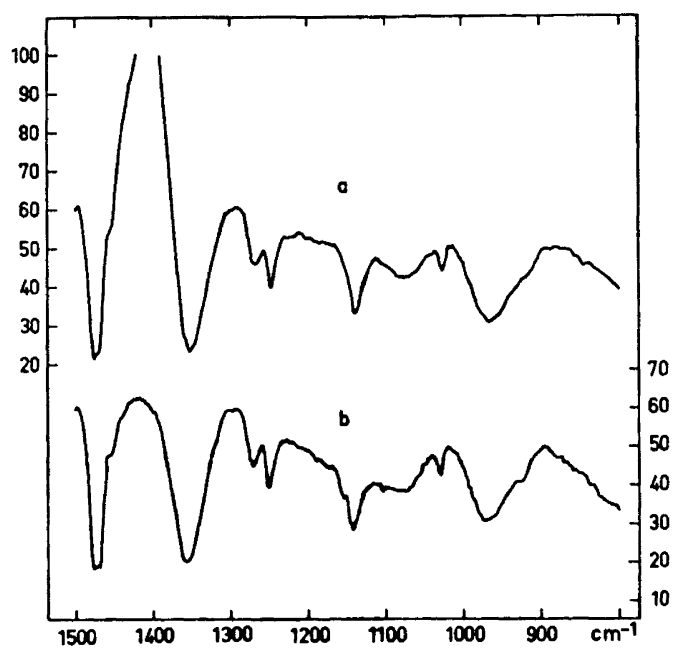

Fig 1. Spectra of sodium salicylate + boric acid. (a) $C_{\mathrm{B}}=1.0 \mathrm{M}, C_{\mathrm{S}}=0.5 \mathrm{M}$ (ref. solution $C_{\mathrm{B}}=0.75 \mathrm{M}$ ); (b) $C_{\mathrm{B}}=1.0 \mathrm{M}, C_{\mathrm{S}}=0.5 \mathrm{M}$ (ref. solution $C_{\mathrm{B}}=0.5 \mathrm{M}$ ).

Acta Chem. Scand. 26 (1972) No. 4 


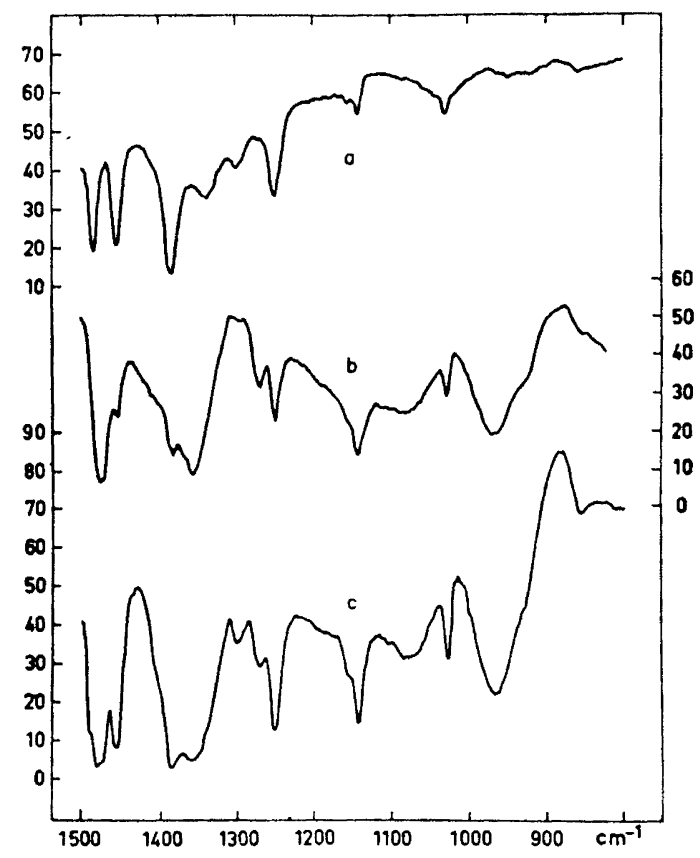

Fig. 2. Spectra of sodium salicylate + boric acid. (a) $C_{\mathrm{S}}=0.5 \mathrm{M}$; (b) $C_{\mathrm{S}}=1.0 \mathrm{M}, C_{\mathrm{B}}=1.0 \mathrm{M}$; (c) $C_{\mathrm{S}}=2.0 \mathrm{M}, C_{\mathrm{B}}=0.8 \mathrm{M}$.

cylate is present as the first complex. As the concentration [S] (the concentration of free salicylate) is then very low, the presence of $\mathrm{BS}_{2}$ can certainly be neglected. Hence this spectrum is representative of BS. This is further borne out by a comparison with Fig. la. In this latter case the reference solution had $\dot{C}_{\mathrm{B}}=0.75 \mathrm{M}$ whereas in the case of Fig. $1 \mathrm{~b}$ the reference solution had $C_{\mathrm{B}}=0.5 \mathrm{M}$. It is seen that an almost perfect compensation of the $\mathrm{H}_{3} \mathrm{BO}_{3}$ absorption band at about $1400 \mathrm{~cm}^{-1}$ is obtained for Fig. $1 \mathrm{~b}$ but a strong overcompensation is found for Fig. la.

In Fig. $2 \mathrm{a}$ the spectrum of pure sodium salicylate $(0.5 \mathrm{M})$ is given. A comparison between Fig. 2 and Fig. $1 \mathrm{~b}$ then gives information on the new absorption bands that appear on formation of BS.

1. The bands at 1480 and $1455 \mathrm{~cm}^{-1}$ disappear and instead one, or possibly two, bands at $1470 \mathrm{~cm}^{-1}$ are formed.

2. The band at $1387 \mathrm{~cm}^{-1}$ is shifted to $1359 \mathrm{~cm}^{-1}$ and broadened.

3. The band at $1340 \mathrm{~cm}^{-1}$ disappears.

4. A new band appears at $1269 \mathrm{~cm}^{-1}$.

5. Two new bands appear at 1080 and $965 \mathrm{~cm}^{-1}$.

6. All other bands are almost unaffected by the complex formation. 


\section{INTERPRETATION OF THE SPECTRA}

The following rationalisations can now be made:

1. The bands at 1480 and $1455 \mathrm{~cm}^{-1}$ are to be related "to the " $19 \mathrm{~A}$ " and " 19 B" vibration modes of the aromatic ring system ${ }^{5}$, as is also probably the band system at $1470 \mathrm{~cm}^{-1}$ of the complex.

2. The bands at $1387(1359) \mathrm{cm}^{-1}$ are the sym. carboxylate vibrations. A shift towards lower frequencies of this is usually found ${ }^{6}$ upon coordination.

3 . The band at $1340 \mathrm{~cm}^{-1}$ most probably corresponds to a $\delta \mathrm{C}-\mathrm{O}-\mathrm{H}$ mode, as this band disappears for a salicylate solution that is $3 \mathrm{M}$ with respect to $\mathrm{NaOH}$ (Fig. 3a).

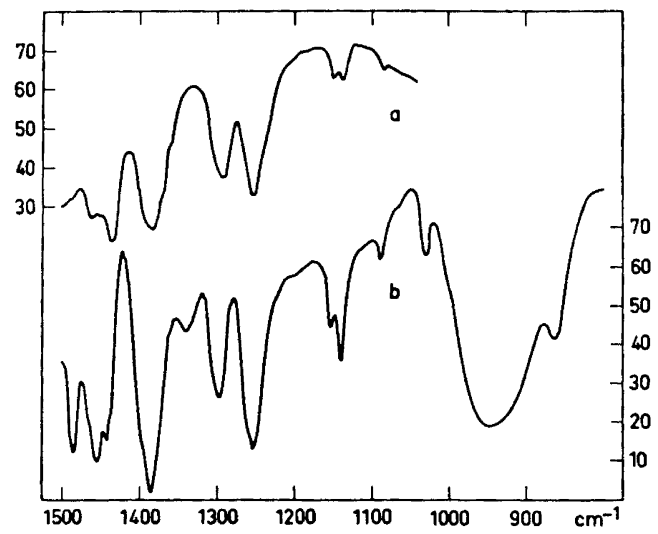

Fig. 3. (a) Spectrum of $0.7 \mathrm{M}$ sodium salicylate in $3 \mathrm{M} \mathrm{NaOH}$; (b) spectrum of sodium salicylate $(1.6 \mathrm{M})$ and sodium borate $(0.8 \mathrm{M})$ at $\mathrm{pH} \approx 13$.

As no band corresponding to this can be found in the complex spectra (within the spectral range investigated) this is support for our formulation of the complex BS, i.e. without a proton on the $\mathrm{C}-\mathrm{O}$ group.

4. The band at $1269 \mathrm{~cm}^{-1}$ probably corresponds to the $\mathrm{C}-\mathrm{O}$ stretching mode in the complex, shifted to this position from $1250 \mathrm{~cm}^{-1}$. However, it can be observed that this latter band is still found in the spectrum of the complex $(c f$. Fig. $1 \mathrm{~b}$ ). We cannot explain this in any other way than that there is such a strong bonding to the boron atom that a splitting of the phenolic $\mathrm{C}-\mathrm{O}$ stretching mode occurs, i.e., the $\mathrm{C}-\mathrm{O}$ group can no longer be regarded as a separate unit but is incorporated in the chelate ring and participates in the skeletal vibrations of the ring.

5. The two bands at 1080 and $965 \mathrm{~cm}^{-1}$ correspond to a splitting of the triply degenerate $\mathrm{BO}_{4} v_{3}$ vibration. The absorption of $\mathrm{B}(\mathrm{OH})_{4}^{-}$occurs at $945 \mathrm{~cm}^{-1}$ (cf., e.g. Ref. 7). This fact is very important ${ }^{1}$ as it shows that the boron atom is really tetracoordinated also in the first complex.

Actually it would be expected that the $\nu_{3}$ vibration mode should give rise to three absoption bands for symmetry $C_{2 v}\left(\mathrm{BS}_{2}\right)$ or lower symmetry (BS). Possibly the shoulder at about $915 \mathrm{~cm}^{-1}$ is an indication of this (Fig. $1 \mathrm{~b}$ ). 
The splitting of the $v_{\mathrm{BO}}$ vibration could be related to the shift of the $v_{\text {coo }}$ in the case of the lactate complexes previously investigated. ${ }^{1}$ The present pair of values $\Delta v_{\mathrm{BO}}$ and $v_{\mathrm{Coo}}$ does not seem to fit the linear relation then ${ }^{1}$ found. However, we have found above that the bonding between the boron atom and the phenolic oxygen is quite strong so it is reasonable to assume that it is this bonding rather than that to the carboxylate group that causes the splitting of the $v_{3}$ band.

6. All other bands, not affected by coordination, i.e. the band at $1030 \mathrm{~cm}^{-1}$ and the doublet at 1146 and $1158 \mathrm{~cm}^{-1}$, are most probably related to the aromatic ring vibrations " 5 " and " $(9 \mathrm{~A}, 9 \mathrm{~B})$ ", respectively.

\section{INTERPRETATION OF THE COMPLEX EQUILIBRIA}

The fact that the band at $1455 \mathrm{~cm}^{-1}$ can be attributed solely to the free ligand makes it possible to perform a rough calculation of [S] for any solution of composition $C_{\mathrm{B}}, C_{\mathrm{s}}$. From the spectrum of pure salicylate (Fig. 2a) the absorbance $A_{1455}$ at $C_{\mathrm{S}}=0.5 \mathrm{M}$ can be calculated and [S] can be obtained from $A_{1455}$ of the other spectra. The results of these calculations are given in Table 1. The accuracy, of course, depends upon how the background line is drawn in each case.

Furthermore, the mean ligand number, $\bar{n}$, can now be calculated:

$$
\bar{n}=\left(C_{\mathrm{S}}-[\mathrm{S}]\right) / C_{\mathrm{B}}
$$

The results of this latter calculation are given in Table 1 and Fig. 4. Now, applying the method of Bjerrum ${ }^{8}$ in its simplest form one obtains the formation constants

$$
\begin{gathered}
K_{1}=\beta_{1}=1 /[\mathrm{S}] \bar{n}_{=0.5} \\
K_{2}=1 /[\mathrm{S}] \bar{n}_{=1.5}
\end{gathered}
$$

Table 1. Absorbance data of some solutions $\left(C_{\mathrm{B}}, C_{\mathrm{S}}\right)$ for the band at $1455 \mathrm{~cm}^{-1} \cdot(\mathrm{pH}=7$, except where otherwise stated.)

\begin{tabular}{|l|l|l|l|l|l|l|}
\hline $\begin{array}{c}C_{\mathrm{S}} \\
(\mathrm{M})\end{array}$ & $\begin{array}{c}C_{\mathrm{B}} \\
(\mathrm{M})\end{array}$ & $A_{1455}$ & $\begin{array}{l}{[\mathrm{S}]} \\
(\mathrm{M})\end{array}$ & $-\log [\mathrm{S}]$ & $\bar{n}$ & \\
\hline 0.5 & 0 & 0.331 & 0.5 & & & Fig. 2a \\
0.5 & 1.0 & 0.036 & 0.05 & 1.3 & 0.45 & Fig. 1b \\
0.75 & 1.0 & 0.073 & 0.11 & 0.96 & 0.64 & Fig. 2b \\
1.0 & 1.0 & 0.111 & 0.17 & 0.77 & 0.83 & Fig. 2c \\
2.0 & 0.8 & 0.62 & 0.94 & 0.03 & 1.33 & \\
0.75 & 0.5 & 0.193 & 0.29 & 0.54 & 0.92 & \\
1.0 & 0.5 & 0.313 & 0.47 & 0.32 & 1.05 & \\
1.5 & 0.5 & 0.615 & 0.93 & 0.25 & 1.14 & \\
1.0 & 0.25 & 0.453 & 0.69 & 0.16 & 1.26 & \\
1.5 & 0.25 & 0.786 & 1.19 & -0.08 & 1.24 & \\
1.8 & 0.9 & 0.65 & 0.97 & 0.01 & 0.91 & $\mathrm{pH}=8$ \\
\hline
\end{tabular}

Acta Chem. Scand. 26 (1972) No. 4 


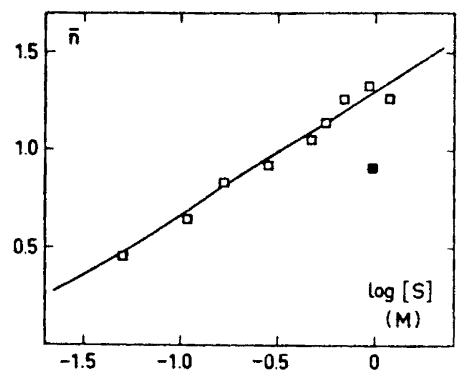

Fig. 4. Experimental values of $\bar{n}$ at $\mathrm{pH}=7$ $(\square)$, at $\mathrm{pH}=8$ ( $)$. The points $(\bar{n}=0.5$, $\log [\mathrm{S}]=-1.22)$ and $(\bar{n}=1.5, \log [\mathrm{S}]=0.28)$ have been read from a rough curve through the points $(\square)$. The full-drawn line is calculated from the stability constants thus estimated.

Although we have only a few experimental points, and thus hardly can expect to get the two parameters with any great confidence, it is seen (Fig. 4) that the points fall rather well on a smooth curve, a fact that facilitates interpolation and extrapolation. The resulting values are

$\beta_{1}=17 \pm 3 \quad \mathrm{M}^{-1}$ and $K_{2}=0.5 \pm 0.3 \quad \mathrm{M}^{-1}$

If we now combine $\beta_{1}$ and $K_{2}$ by the relation

$$
\beta_{2}=\beta_{1} K_{2}
$$

we obtain $\beta_{2}=9 \pm 7 \mathrm{M}^{-2}$ and we can consequently calculate $\vec{n}$ at any value of [S] as a check of the formation curve. Alternatively, and with more confidence, one can estimate $\beta_{2}$ from the relation $\beta_{2}=1 /[\mathrm{L}]^{2} \bar{n}=1$. This yields $\beta_{2}=9 \pm 5 \mathrm{M}^{-2}$.

Furthermore, and more interesting, we can check the validity of formula (6) in the following way. Whereas all measurements hitherto discussed were made at $\mathrm{pH}=7$, one spectrum was recorded at $\mathrm{pH}=8$. The absorbance at $1455 \mathrm{~cm}^{-1}$ of this spectrum is included in Table 1 together with the corresponding value of $\bar{n}$. Now, if formulae (1) and (4) are correct, an increase of $\mathrm{pH}$ by one unit will not affect $\beta_{1}$ but as $K_{2}^{\prime}$ contains the factor [ $\mathrm{OH}^{-}$] it must hold that

$$
\left(K_{2}\right)_{\mathrm{pH}=8}=0.1\left(K_{2}\right)_{\mathrm{pH}=7}
$$

Consequently, $\left(\beta_{1}\right)_{\mathrm{pH}=8}=17 \mathrm{M}^{-1}$ and from the relation $(10)\left(\beta_{2}\right)_{\mathrm{pH}=8}=0.9$. From these values we can calculate $\bar{n}_{\mathrm{pH}=8}$ at $[\mathrm{S}]=1.0 \mathrm{M}$. The result is

$$
\bar{n}=\frac{17+2}{1+17+1}=1.0
$$

This value is in rather good agreement with the experimental one (Fig. 4), thus indicating the correctness of our general formulation of the equilibria (1) and (4).

It is also interesting to compare our value of $\beta_{1}$ with that given by Kolthoff ${ }^{3}$ from measurements of the solubility of silver salicylate in boric acid at a lower value of the ionic strength than we have used. He reports $\beta_{1}=22 \pm 2 \mathrm{M}^{-1}$ which is in reasonable agreement with our value. It must be remembered that as the formula (1) has one charged unit on each side, the variation of the activity coefficients with the ionic strength will probably cancel out to a large extent in the expression for $\beta_{1}$. Thus the fact that almost the same values of $\beta_{1}$ 
are obtained at $\mathrm{pH}=5$ (Kolthoff ${ }^{3}$ ) and at $\mathrm{pH}=7$ (present work) indicates the correctness of the formulation of (1), i.e. the splitting off of the phenolic proton.

The stability constants thus estimated indicate that the salicylate-boric acid complex system is a relatively weak one. This is further borne out by our measurements at a high $\mathrm{pH}(\mathrm{pH} \approx 13$; Fig. $3 b)$ from which it can be seen that the spectrum is a superposition of that of the salicylate and $\mathrm{B}(\mathrm{OH})_{4}{ }^{-}$ ions. This means that the equilibria (1) and (4) are completely displaced to the left hand side as the boric acid - borate ion equilibrium is itself displaced entirely in favour of the borate ion at that $\mathrm{pH}$.

The financial support of the Swedish Natural Science Research Council and of Fondazione F. Giordani, Rome, Italy, is gratefully acknowledged.

\section{REFERENCES}

1. Larsson, R. and Nunziata, G. Acta Chem. Scand. 24 (1970) 2156.

2. Meulenhoff, J. Rec. Trav. Chim. 44 (1925) 161.

3. Kolthoff, I. M. Rec. Trav. Chim. 45 (1926) 607.

4. Spinner, E. J. Chem. Soc. B 1967874.

5. Wilson, E. B. Phys. Rev. 45 (1934) 706.

6. Nakamoto, K., Fujita, J., Tanaka, S. and Kobayashi, M. J. Am. Chem. Soc. 79 (1957) 4904.

7. Goulden, J. D. S. Spectrochim. Acta 9 (1959) 657.

8. Bjerrum, J. Metal Ammine Formation in Agueous Solution, Diss., P. Haase and Søn, Copenhagen 1941.

Received August 19, 1971. 